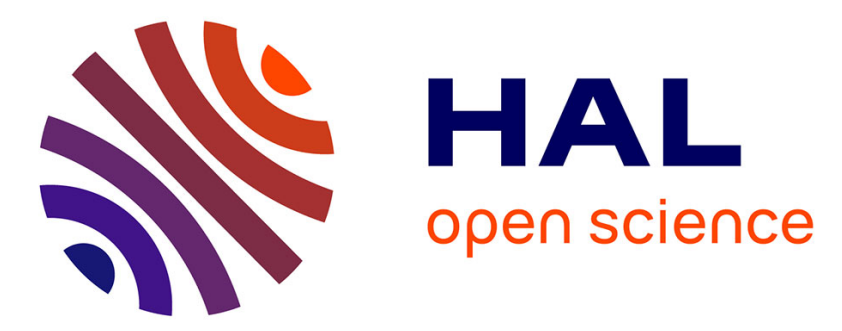

\title{
Proof of concept of plasmonic thermal destruction of surface cancers by gold nanoparticles obtained by green chemistry
}

Maroua Ben Haddada, Dimitri Koshel, Zhang Yang, Weiling Fu, Jolanda Spadavecchia, Sabrina Pesnel, Anne-Laure Morel

\section{To cite this version:}

Maroua Ben Haddada, Dimitri Koshel, Zhang Yang, Weiling Fu, Jolanda Spadavecchia, et al.. Proof of concept of plasmonic thermal destruction of surface cancers by gold nanoparticles obtained by green chemistry. Colloids and Surfaces B: Biointerfaces, 2019, 184, pp.110496. 10.1016/j.colsurfb.2019.110496 . hal-02357083

\section{HAL Id: hal-02357083 https://hal.science/hal-02357083}

Submitted on 9 Nov 2019

HAL is a multi-disciplinary open access archive for the deposit and dissemination of scientific research documents, whether they are published or not. The documents may come from teaching and research institutions in France or abroad, or from public or private research centers.
L'archive ouverte pluridisciplinaire HAL, est destinée au dépôt et à la diffusion de documents scientifiques de niveau recherche, publiés ou non, émanant des établissements d'enseignement et de recherche français ou étrangers, des laboratoires publics ou privés. 


\section{Proof of concept of plasmonic thermal destruction of surface cancers by gold nanoparticles obtained by green chemistry}

Maroua Ben Haddada $^{1,2}$, Dimitri Koshel $^{1}$, Zhang Yang $^{3}$, Weiling $\mathrm{Fu}^{3}$, Jolanda Spadavecchia $^{2}$, Sabrina Pesnel $^{1}$, Anne-Laure Morel ${ }^{1 *}$

${ }^{1}$ TORSKAL nanosciences, 2 rue Maxime Rivière, 97490 Sainte-Clotilde, La Réunion France

${ }^{2}$ CNRS, UMR 7244, CSPBAT, Laboratoire de Chimie, Structures et Propriétés de Biomatériaux et d'Agents Thérapeutiques, Université Paris 13, Sorbonne Paris Cité, Bobigny, France

${ }^{3}$ SOUTHWEST HOSPITAL, Third Military Medical University (TMMU), Chongqing, China

Corresponding authors: annelaure.morel@torskal.fr

KEYWORDS: green nanomedicine, gold nanoparticle, medicinal plant, plasmonic photothermal therapy, hyperthermia

\section{Abstract}

A greener approach for the design of surface plasmon resonant gold nanoparticles has been obtained with a hydrosoluble fraction of an endemic asteraceae medicinal plant. This medicinal plant is originated from Indian Ocean and demonstrates its bioreducing activity in the design of stable green nanomedicine in aqueous media. This article describes the preclinical assessment of the efficacy of these novel nanocandidates on murine model by intratumoral and intravenous injections. It definitely demonstrates two key points in the treatment of cancer: 1) optimization of the tumor microenvironment targeting by specific 
ligands for a limited damage on healthy tissue, 2) the need to screen the specific irradiation dose (time, power) taking into account the type of tumor.

\section{Introduction}

Green nanomedicine is inspiring anew trend of treating serious diseases[1]like cancers in a global scale. This green nanomedicine is a novel concept mainly emerging in North and South Asia, and to a lesser extent in Indian Ocean[2] where medicinal plants arerequired as bioreactants in modern nanotechnology. This concept presents ecological and scientific aspects. Thetechnological transfer in industrial scale will require no/few synthetic chemical compounds and will cause limited damages on the environment. The metal (gold) is the active principle; medicinal plants are herein used for the design of the nanoparticles and their stabilization before the ligand exchange between targeting moieties and flavonoids. The destruction of the tumor environment is remotely activated by a noninvasive medical device (NIR laser).

The smallest nanoparticles are interesting for targeting cell nuclei (gene therapy and drug delivery) and for size effects at the nanoscale. Studies reported that sub10 $\mathrm{nm}$ sized nanoparticles are obtained by reverse synthesis[3], i.e. by inverting the order of introduction of the reagents.

Currently, the gold standard method for the treatment of surface cancersis essentially surgery. The operation involves removing the tumor and a few millimeters of the healthy tissue surrounding it. This method follows the precautionary principle and presents the disadvantage to requirelarge surgical margin leading to unaesthetic scars on skin. The goal is to ensure total removal of malignant cells. 
The issue is double: first detect at early stage the malignant cell in combination with existing medical imaging, second reduce the margin around the malignant area when operating the surgical excision.

During this decade, gold nanoparticles (AuNP)demonstrated their biocompatibility, low toxicity and easy way of functionalization. Previous studies reported the synthesis of controlled and reproducible reactions leading to stable and biocompatible gold nanoparticles (AuNP)[2]. Well known reverse synthesis[3]usually leads to sub10nm nanoparticles. Synthetic chemical compounds were here replaced by crude extracts for the formation of stable water soluble gold nanoparticles in a simple and ecological manner.

SPRgold nanoparticles allows photothermal therapy (PPTT)by inducingexalted hyperthermia in the specific area containing nanoparticles[4]. Due to the low penetration depth of the NIR laser in the tissues, PPTT is adapted to surface cancer, as skin cancers, or other cancers accessible via an endoscope as lung, colorectal or pancreatic cancers. The targeting moiety is a cyclo-peptide able to specifically bind to endothelial receptors and melanoma cells[5], [6]. In the present study, the antitumor activity of gold nanoparticles via a photothermal effect was assessed on a murine model: melanoma. The therapeutic efficiency of the treatment is compared with conventional treatment. Among the existing published results on PPTT, few of them managed to design the optimal parameters for the induction of hyperthermia in the region of interest containing the nanoparticles. They focus on the destruction of the tissue leading to necrosis, thus also causing the destruction of the healthy microenvironment surrounding the tumor. This publication herein reports in vitro and in vivo results showing the proof of concept of the efficiency of green nanomedicine as ecological and nontoxic nanoparticles for the treatment of surface and surgical access cancers. 


\section{Results and discussion}

\subsection{Strategic choice of plants for green synthesis}

Prior to the selection of the plant, we considered the possible in vivo side effects induced by the plant extracts either by dissociation of physisorbed molecules during the vectorization or by nonspecific targeting of the tumor area. The choice of medicinal plants was done according to the medicinal property of the plant used, and ecological criteria. The asteraceae plant herein studied is well known in traditional medicine in Reunion Island. In external and internal use this plant is recommended for skin problem as eczema [7]. We focused on ecological extraction with no synthetic chemical compounds. No sulfide group is present in the crude mixture of plant extracts [8] which may lead to main carbonyl coordination as chemical link between organic molecules and gold nanoparticles.

\subsection{Synthesis of green gold nanoparticles and their characterization}

AuNPs were synthetized as previously described by Morel et al[2].The reverse synthesis protocol led to $15 \mathrm{~nm}$ size and spherical shape nanoparticles as previously obtained with a mixture of crude extract and quercetin [9]. These results demonstrate the role of a strong natural bioreducer added in the medium, quercetin or isomer, for the design of small nanoparticle and also demonstrates the possibility to use reverse synthesis in substitution to quercetin for the design of an ecofriendly and costless process.

The macroscopic color change of the brown plant extract solution after the introduction ofthe tetrachloroauric acid indicates the expected formation of $15 \mathrm{~nm}$ sized spherical nanoparticles.

This was confirmed by the UV-Visible absorption spectra in Figure IA (supplementary data). AuNPs had absorption maximum in the range of 500-600 $\mathrm{nm}$ due to SPR phenomena. The characteristics of this plasmon band (position, width, spectral amplitude and sensitivity 
for light polarization) depend not only on intrinsic properties of nanoparticles (composition, structure, size and shape) but also of their dispersion and their local environment. The peak optical density (OD), or absorbance of the sample, correlates linearly to the concentration of nanoparticles in solution. The AuNP showed the SPR band around $533 \mathrm{~nm}$ in the visible region. This single band also indicated that the obtained gold nanomaterials are mainly spherical in shape, in accordance with the Mie theory, did not form agglomerates and corresponds to a size of around $15 \mathrm{~nm}$ according to the literature[10].In UV-Vis, the disappearance of the absorption of $\mathrm{Au}$ (III) at $290 \mathrm{~nm}$ is due to the reduction of gold salts in the presence of bioreducers that are plant extracts.

The different centrifugation of nanoparticles as well as the disappearance of the peak at 290m (UV-visible) in favor of SP at $524 \mathrm{~nm}$ demonstrate the reduction of metal salts and the formation of $\mathrm{Au}^{0}$.After the addition of polymer, the UV-Visible spectra of AuNP@G did not present a blue shift but a decreasing intensity without formation of agglomerates. This can be explained by the increasing particle gap after the grafting of the carbohydrate on top of the AuNPs. Moreover, the UV-visible spectra of AuNP@G@P showed a slight red shift (5 nm) in the plasmon peak arising from a small change in the refractive index around the AuNP due to the peptide coating.

The stability of colloid was monitored by UV-Visible absorption spectra. The obtained AuNP was stable during storage and could be maintained at room temperature for more than one month without obvious changes (data not shown). This stability of AuNP implied that the surfaces of the gold nanoparticles were well protected first by the associated plant extract, then exchanged by the carbohydrate.

The stabilization of AuNP with carbohydrate was confirmed by Raman spectroscopic analysis (Figure IB supplementary data). This analysis showed that the specific functional groups of the AuNP@G have the same chemical characteristics than the pure polymer, indicating the 
molecular interaction with the AuNP surface. The spectrum of a high concentration carbohydrate in water presents several vibrational peaks at $512,845,912,1064$, and $1120 \mathrm{~cm}^{-}$ 1. After functionalization with the peptide, there is no significant change on the Raman spectra, this can be explained by the high gap to metal nanoparticle distance. The larger distance between the peptide and the nanoparticle surface did not show significant enhancement.

Additionally, we performed dynamic light scattering (DLS) characterization and TEM imaging to verify the diameter and morphological characteristics of formed AuNP before and after functionalization (Table 1 - Figure II). TEM images show AuNP@G and AuNP@G@P appearing as dark spots with a size around $13.96 \pm 2.45 \mathrm{~nm}$ and $13.81 \pm 2.83 \mathrm{~nm}$ respectively. These latter gold nanomaterials appearmainly as spherical shape. According to the DLS, average diameter of AuNP is $35.92 \pm 0.8 \mathrm{~nm}$. This diameter takes into account the plant extract layer formed around the nanoparticle. Notice the larger hydrodynamic diameter than the 'dry' diameter obtained in TEM, due to solvation, hydrogen bonding and van der Waals effects. A significant increase in the particle size for AuNP@G, as compared to AuNP, could also be explained by the adsorption of polymer to the surface. After interaction with the peptide, the average particle size in DLS of AuNP@G@P is $68.67 \pm 1.08$ nm.

The zeta potential of AuNP was -26.2 due to the negative charge of hydroxyl group of flavonoids coating the nanoparticles and responsible for their stability. After this carbohydrate adsorption, the zeta potential became more negative due to the hydroxyl function. Furthermore, zeta potential was maintained negative after the conjugation of the peptide and conferred a high stability to the nanoparticle suspensions.

The chemical composition of the upper shell of the nanoparticles was probed by X-ray photoelectronspectroscopy (XPS) (FigureIII supplementary data). This characterization method demonstrates the evolution of the rate of elements and this corroborates the presence 
of an organic shell stabilizing the nanoparticles. This shell is in majority constituted with carbon $(60 \%)$ and oxygen $(30 \%)$. The successive steps of functionalization show clearly the increase of the ratio $\mathrm{C} / \mathrm{Au}, \mathrm{O} / \mathrm{Au}$ and $\mathrm{C} / \mathrm{O}$ as indicated inTable $\mathrm{I}$. Considering that biomolecules such as peptides, carbohydrates and flavonoids are constituted with a higher rate of carbon than oxygen, we can deduce that the ratio $\mathrm{C} / \mathrm{O}$ would be higher after the grafting of biomolecules. Depending on the nature of amino acids, the ratio $\mathrm{C} / \mathrm{O}$ is at the average of 10 , higher than those of flavonoids or carbohydrate. Regarding the evolution of $\mathrm{C} / \mathrm{Au}, \mathrm{O} / \mathrm{Au}$ and $\mathrm{C} / \mathrm{O}$ we can deduce that the peptide is grafted on the top of the shell.The O1s at $532.93 \mathrm{eV}$ demonstrates a carbonyl coordination bond to the gold surface atom of the nanoparticle.

\subsection{In vitro biological activity of AuNP@G@P}

Carbohydrate was added [11] for the preferential accumulation of the nanoparticles in the region of interest, high area of angiogenesis.Kattiand aldemonstrated the double influence of carbohydrates (maltose and gum arabic) in the stabilization of the nanoparticles and the targeting property in an active way. It is known that the shape and size of nanoparticles directly influences the ability of nanoparticles to reach the microenvironment of tumors and thus the effectiveness of treatment[12].

A. K.Renganetal first reported the design of degradable liposomes as potential candidate for the liberation of small $5 \mathrm{~nm}$ sized nanoparticles in the region of interest[13]. This candidate is well adapted for the renal clearance $(\mathrm{NpAu}=5.5 \mathrm{~nm})$ but requires high concentration of AuNP at the surface of liposome for an efficient PPTT atnon-lethal power density for healthy tissue $\left(0.9 \mathrm{~W} / \mathrm{cm}^{2}\right)$. The best compromise seems to be the design of $10-15 \mathrm{~nm}$ sized spherical nanoparticles leading to poor capture by hepatosplenic system and allowing the destruction of tumor zone at non-lethal power density for healthy tissue. 
Our strategyfocuses on theuse of small nanoparticles (15nm spherical shape) for the treatment of surface cancers with a high level of angiogenesis. The best administration mode has been studiedto launch the higher rate of accumulation of nanotheranosticin the region of interest. This required a careful research of parameters to avoid the destruction of healthy tissue but inducing irreversible damages to cells that have internalized nanoparticles.

\subsubsection{Cellviabilitymeasurement}

Cell viability was assessed after the incubation ofAuNP@G@Pwith tumor cells at various concentration for $24 \mathrm{~h}$ or $48 \mathrm{~h}$. After $24 \mathrm{~h}$ incubation, as shown in Figure 1, AuNP@G@P did not present significant cytotoxic effect on the viability of tumor cells for OD 0.03-0.15. After 48h incubation, AuNP@G@P did not show significant cytotoxic effect on the viability of tumor cells for $\mathrm{OD}<0.38$. The optical density (OD)0.15 was considered as the highest tested dose to study biological activity of AuNP@G@P.

\subsubsection{Cellinternalization of AuNP}

Cell internalization of the AuNP@G@P was assessed by microscopy and absorbance measurements. Figure 2B shows black spots on the bright field image and dark spots on the dark field image corresponded to nanoparticles aggregates which were not visible on the nontreated cells and more concentratedwith larger concentration of nanoparticles. Figures $\mathbf{3 B}$ and 3Cindicate that internalization is dose and time dependent. Higher concentrations of nanoparticles led to higher internalization ratesof nanoparticles for both type of cells.

\subsubsection{Preliminary in vitro hyperthermia in solution}

Once the internalization was studied,preliminary in vitro hyperthermia assessments were performed with the finalcandidate AuNP@G@P. The purpose was to study the plasmonic phototothermalcapability in solution. Under continuous irradiation, NPAu demonstrated a 
linearincrease of temperature in function of time leading totwo maxima of $\Delta \mathrm{T}=$ $2.8^{\circ} \mathrm{Cand} 13.4^{\circ} \mathrm{C}$ respectively at 0.2 and $0.6 \mathrm{~W} / \mathrm{cm}^{2}$ (Figure III supplementary data). Figure

4A shows an increase of temperaturedependingon the quantity of injected AuNP. The mediated plasmonic hyperthermia induced by AuNP seems to be time and concentration dependent at any continuous irradiation dose.

Hyperthermia alters the expression of several genes related to cell proliferation and differentiation, i.e. p53 (cell cycle regulator gene), Bax and Bcl-2, leading to apoptosis[14].

\subsubsection{In vitro hyperthermia measured in presence of cells}

Once the capability of AuNP to mediate hyperthermia was demonstrated in solution, the assessment of the PPTT was performed in biological conditions, in the presence of MIAPaCa-2 cells. The power density of the laser was set at $0.2 \mathrm{~W} / \mathrm{cm}^{2}$ considering the maximal permissible exposure of skin as per ANSI regulation for a continuous irradiation mode at 808 nm. This condition did not lead to skin and subcutaneous tissue damages on rats[15]. Figure 4Bdemonstrated that the treatment at $0.2 \mathrm{~W} / \mathrm{cm}^{2}$ led to fewer living MIA-PaCa-2cells $24 \mathrm{~h}$ after the treatment than in the control. Moreoverno dead cells were visible by optical microscope nor by the detection of cleaved caspase $3 / 7$ which consequentlyindicates a cell growth inhibition at $0.2 \mathrm{~W} / \mathrm{cm}^{2}$.Same results were observedat $0.45 \mathrm{~W} / \mathrm{cm}^{2}$. In conclusion, these experimentations report here that these power densities $\left(0.2\right.$ and $\left.0.45 \mathrm{~W} / \mathrm{cm}^{2}\right)$ induced reversible damages but inefficient hyperthermia for the cell destruction by heat. Higher power densities wereassessed on SK-MEL-28: 0.6 and $0.9 \mathrm{~W} / \mathrm{cm}^{2}$. Both induced cell death (Figures5A and 5B) but severe cellular damaged was caused at $0.9 \mathrm{~W} / \mathrm{cm}^{2}$ even without the AuNP. The optimal in vitroconditions seem to be AuNP solution with OD $=0.15$ with a laser power density $=0.6 \mathrm{~W} / \mathrm{cm}^{2}$. Indeed, with these conditions, we observe cell death while 
exposing the cells to either AuNP or NIR light individually, which did not compromise cell viability.

Even if the main goal is to manage to kill the tumor cells, the best way to achieve it would be to induce tumor cell apoptosis instead of necrosis. Indeed, the risk with necrosis is to induce inflammation and edema in the treated tissue while there are generally no noticeable symptoms related to the apoptosis process. Annexin V-PI staining test was performed $24 \mathrm{~h}$ after the PTT treatment in order to evaluate the cell death mechanism. PTT treatment induced apoptosis with a significant increase in late apoptosis $\left(\right.$ Annexin $\left.\mathrm{V}^{+} / \mathrm{PI}^{+}\right)$as shown in Figure 6A. The presence of cells in late apoptosis was further confirmed by the observed induction of caspase 3/7 activity $24 \mathrm{~h}$ after PTT application.

Despite the high power densityapplied to the skin (i.e. $0.6 \mathrm{~W} / \mathrm{cm}^{2}$ is three times higher than the maximal permissible exposure skin), we may consider that several teams observed a difference of efficiency between in vitro and in vivo condition [16], [17]. They reported the difficulty to generate an optimal hyperthermia inducing the in vitro destruction of cells, in comparison with in vivo conditions due to the absence of the microenvironment, as described by Hanahanet al[18].

\subsection{In vivoefficacy assessment of the treatment by NIR irradiation}

The solid tumors are considered as microenvironment with an assembly of distinct cell types[19]: cancer stem cell, cancer cell, cancer associated fibroblast, endothelial cell, pericyte, immune inflammatory cells.

One issue that came up is the determination of the best administration route leading to an important accumulation in the region of interest. As demonstrated by Katti and al[11], the coating has an influence on the target property of the nanoparticles. 
AuNP@G@P were injected to tumor bearing mice in two administration routes: intravenous and intratumoral. Thebiodistribution of AuNP was assessed by measuring the quantity of gold in the main organs and tumor using ICP-MS analysis, $4 \mathrm{~h}$ or $24 \mathrm{~h}$ post-administration.

\subsubsection{Intravenous injection}

As reported in Figure 7A, after $4 \mathrm{~h}$ post-injection, the highest quantities of gold are concentrated in the liver $(23,039 \pm 3,064 \mu \mathrm{g} / \mathrm{kg})$ and in the spleen $(3,014 \pm 362 \mu \mathrm{g} / \mathrm{kg})$. Other organs and tumor have small quantity of gold around $100 \mu \mathrm{g} / \mathrm{kg}$.

After $24 \mathrm{~h}$ post-injection, the quantity of gold decreased in the liver and increased in the spleen. No significant difference was observed in the tumor and other organs. The presence of AuNP@G@P in the spleen indicated that a part of the AuNP were cleared by the reticuloendothelial system (RES) with splenic clearance. But the main part was uptaken by the liver for hepatic clearance.

\subsubsection{Intratumoral injection}

In order to get a higher concentration of nanoparticles inside the tumor, we also assessed the biodistribution after intratumoral injection. As shown in Figure 7B, 4h after intratumoral injection, the main part of the gold was present into the tumor $(16,697 \pm 6,684 \mu \mathrm{g} / \mathrm{kg})$ while the quantity was lower than $200 \mu \mathrm{g} / \mathrm{kg}$ in the other organs. Despite the quantity decreased $24 \mathrm{~h}$ post injection, AuNP@G@P were still present in the tumor without significant rise in other organs. Meanwhile, we assume that AuNP were eliminated by kidneys.

To demonstrate that a single dose of AuNP associated to laser could destroy tumor cells, we injected AuNP in tumor bearing mice and compared with injected PBS (Figure 6B). One hour later, the tumor was irradiated for 20 minutes $\left(808 \mathrm{~nm} ; 1.5 \mathrm{~W} / \mathrm{cm}^{2}\right)$ and the tumor volumes were monitored every day for 3 days. B16F10 melanoma are black mice, present highly vascularized and tick tumor $(7 \mathrm{~mm})$ at the beginning of the treatment. For these reasons, the study required higher power density than for in vitro studies. 
AuNP@G@P coupled with laser irradiation showed a high antitumor activity according to the criteria of Corbett et al[20](T/C $\leq 10 \%$ and $\mathrm{rAUC} \leq 50 \%)$ and were not toxic at the injected dose. Indeed, body weight were monitored over time and showed no obvious losses (no weight loss > 20\%). An inhibition of tumor growth by $77 \%$ (in all mice and a partial regression in four mice) was observed in the AuNP group while no inhibition of tumor growth was observed in the laser group.

\section{Conclusion}

This article reports the proof of concept of plasmonic photothermal treatment of surface and surgical access cancers by green nanogold theranostic. The challenge consisted in the noninvasive destruction of cancer cells in a single nontoxic dose and activated after intratumoral injection by non-ionizing irradiation.

These candidates are obtained by a greener approach than previous process already developed in our team, using plant extracts, water and gold salts. These latter candidates demonstrate the photothermal effect both in vitro and in vivo skin cancer murine model. The exposure of the gold nanoparticles to NIR allowed a temperature increase sufficiently high to induce cell death even at low power density. This paper highlights the design of personalized physical parameters of PPTT inducingirreversible damages and leading to a "cleaner" tumor destruction without causing the necrosis of healthy tissue.Intratumoral injection allowed higher amounts of AuNP into the tumor and reduced the uptake by the other organs. Considering the surface diseases as skin cancers, one may conclude that an intratumoral injection could optimize the delivery of AuNP inside the tumor to get a better efficacy of the PPTT. 
The actual challenge in cancer therapy is to treat rapidly in an irreversible manner by injecting a single dose of product. The next publication will present the in vivoresults of PPTT on skin cancers for destruction of tumorsat non -lethal irradiation dose without affecting healthy tissue. The next challenge will concern the design of theranostic by the combination with in vivo medical imaging for the skin treatment at early stage.

\section{Experimental section}

\section{Reagents and chemicals}

Tetrachloroauric acid $\left(\mathrm{HAuCl}_{4}\right), \mathrm{EDC}, \mathrm{NHS}$, carbohydrate were purchased from SigmaAldrich (Saint-Quentin Fallavier, France). Peptide was purchased from SynVec (University of Bordeaux II, France). The plant (TSK1) was purchased from CAHEB, Reunion Island.

\section{Synthesis of gold nanoparticles (AuNP)}

The gold nanoparticles were synthesized using the method previously described [2] then stabilized by a carbohydrate.

Functionalization by peptide (AuNP@G@P)

3 ml of AuNP@G was mixed with $200 \mu \mathrm{L}$ EDC/NHS mixture and kept for $1.5 \mathrm{~h}$ at room temperature. The solution was centrifuged and redispersed in deionized water. Then $3 \mathrm{ml}$ of

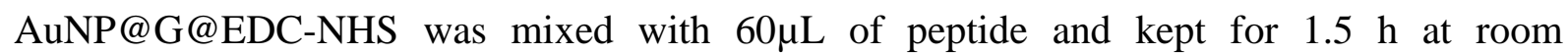
temperature. The solution was centrifuged and redispersed in deionized water.

\section{Characterization of AuNPs}

All the measurements were performed at least in triplicate in order to validate the reproducibility of the synthetic and analytical procedures. 
The UV-Vis absorption spectra of AuNPs solution was recorded by a Perkin Elmer Lambda UV/Vis 950 using standard $1 \mathrm{~mm}$ plastic cells at room temperature. The measurements have been made in the $200-900 \mathrm{~nm}$ spectral range.

Transmission electron microscopy (TEM) images of AuNPs were acquired on a TEM/STEM Technai Osiris microscope (FEI) equipped with a high angle dark field detector operating at $200 \mathrm{kV}$. To conduct TEM analysis, a $3 \mu \mathrm{l}$ drop of AuNP solution previously treated for 5 min in an ultrasonic bath was deposited on carbon-coated copper grid. The sample was left to dry during 30 minutes under ambient air.

Hydrodynamic particles size distribution and zeta potential were measured on a ZetasizerNanoZSP (Malvern Instruments). The measurements were realized at $25^{\circ} \mathrm{C}$.

A ThermoFisher Scientific K-ALPHA spectrometer was used for XPS analysis with a monochromatized AlK $\alpha$ source $(\mathrm{h} v=1486.6 \mathrm{eV})$. The $\mathrm{X}$-Ray spot size was 400 microns for surface point acquisition and 200 microns when sputtering. A pressure of 10-7 Pa was reached in the chamber when transferring drops of liquid onto indium foil. The full spectra (0-1100 eV) were obtained with a constant pass energy of $200 \mathrm{eV}$ and high resolution spectra at a constant pass energy of $40 \mathrm{eV}$. Charge neutralization was applied during analysis. $\mathrm{C} 1 \mathrm{~s}, \mathrm{O} 1 \mathrm{~s}$, Au4f high resolution spectra were fitted and quantified using the AVANTAGE software provided by ThermoFisher Scientific (Scofield sensitivity factors used for quantification).

In vitro biological activity of AuNP@G@P

Origin of tumor cell line - Cell culture

Two cells lines were used: the tumor MIA-PaCa-2 derived from surgical explant of a pancreas carcinoma from a 65-years old Caucasian man and the tumor SK-MEL-28 derived from surgical explant of a malignant melanoma from a 51-years old Caucasian man. Cell lines were 
purchased from ATCC (ATCC® CRL- $1420^{\mathrm{TM}}$ and HTB-72 ${ }^{\mathrm{TM}}$ ) and cultured in DMEM supplemented with $10 \%$ heat-inactivated fetal bovine serum, $2 \mathrm{mM}$ L-glutamine, $20 \mathrm{mM}$ sodium pyruvate, $50 \mathrm{U} / \mathrm{ml}$ penicillin and $50 \mu \mathrm{g} / \mathrm{ml}$ streptomycin. The cell lines were maintained at $37^{\circ} \mathrm{C}$ in $5 \% \mathrm{CO}_{2}$ and $95 \%$ air in a humidified atmosphere.

\section{Cytotoxicity}

Cells were incubated $24 \mathrm{~h}$ or $48 \mathrm{~h}$ with different amount of AuNP $(50 \mu \mathrm{L}$ in $150 \mu \mathrm{L}$ medium) in 96-well culture plate at $37^{\circ} \mathrm{C}$ and $5 \% \mathrm{CO}_{2}$. After that, a standard trypan blue exclusion test of cell viability was performed to determine the cell killing efficiency of AuNP. Cell viability was normalized to a control group without any AuNP.

\section{Evaluation of AuNP internalization}

Cells were incubated $4 \mathrm{~h}$ or $24 \mathrm{~h}$ with different amount of AuNP $(50 \mu \mathrm{L}$ in $150 \mu \mathrm{L}$ medium) in 96-well culture plate at $37^{\circ} \mathrm{C}$ and $5 \% \mathrm{CO}_{2}$. After that, cells were washed with PBS to remove AuNP that were not internalized within the cells. The cells were then trypsinized to get solutions of cells/AuNP in PBS $(200 \mu \mathrm{L})$. The absorption of these solutions was measured with an UV-Vis spectrophotometer (1 mm cuvette). In addition, optical images of the cells were made with the optical microscope of a Xplora Raman microspectrometer (Horiba scientifics) in bright and dark fields.

\section{Evaluation of plasmonic photothermal therapy (PPTT)}

Cells were incubated $24 \mathrm{~h}$ with $\mathrm{AuNP}(50 \mu \mathrm{L}$ in $150 \mu \mathrm{L}$ medium) in 96-well culture plate at $37^{\circ} \mathrm{C}$ and $5 \% \mathrm{CO}_{2}$. After internalization for $24 \mathrm{~h}$, cells were washed with PBS and irradiated by an $808 \mathrm{~nm}$ NIR laser at different power densities (from 0.2 to $0.9 \mathrm{~W} / \mathrm{cm}^{2}$ ) for different time (1 to $9 \mathrm{~min}$ ). During the irradiation the cells were maintained to $37^{\circ} \mathrm{C}$. Cell growth inhibition was determined by measuring 3-(4,5-dimethylthiazol-2-yl)-2,5-diphenyltetrazolium bromide (MTT) dye absorbance by living cells. MTT solution $(2.5 \mathrm{mg} / \mathrm{mL}$ in PBS) was added to each 
well and cells were incubated for $4 \mathrm{~h}$. Formazan crystals resulting from MTT reduction were dissolved by the addition of $10 \%$ SDS in DMSO/acetic acid solution per well. The relative quantity of formazan products formed in each well was detected by reading absorbance at 570 nm. Cell growth was normalized to a control group without any treatment.

Cell apoptosis was measured 24h after NTP by flow cytometry using a dead cell apoptosis kit with annexin V FITC and Propidium Iodide (PI) (ThermoFisher Scientific, France). MIA$\mathrm{PaCa} 2$ cells were seeded into a 24-well culture plate at a density of $2 \times 10^{4}$ cells/well and incubated 24h with AuNP@G@P (OD=0.6; $250 \mu \mathrm{L}$ in $750 \mu \mathrm{L}$ medium $)$ at $37^{\circ} \mathrm{C}$ and $5 \% \mathrm{CO} 2$. The cells without AuNPs were used as a control. After internalization for 24h, the treated cells were then washed with PBS and fresh media was replaced. The cultured cells were then maintained at $37^{\circ} \mathrm{C}$ and irradiated by an $808 \mathrm{~nm}$ NIR laser at a power density of $0.6 \mathrm{~W} / \mathrm{cm}^{2}$ for 9 min. At $24 \mathrm{~h}$ post-treatment, cultures were assayed by flow cytometry using a dead cell apoptosis kit with annexin V FITC and Propidium Iodide (PI) (ThermoFisher Scientific, France). Cells were collected and washed with PBS, centrifuged (1,000 g at $37^{\circ} \mathrm{C}$ for $\left.5 \mathrm{~min}\right)$ and stained with Annexin V-FITC and PI according to the manufacturer's instructions. In addition, the Caspase-Glo3/7 Assay kit was also used to measure caspase 3/7 activation according to manufacturer protocol.

In vivo assessment of the plasmonic photothermal activity of AuNP@G@P

\section{Cell culture}

B16F10 (ATCC® CCL-6475 ${ }^{\mathrm{TM}}$ ) is a murine melanoma cell line from a C57B1/6J mouse. Cell line was cultured in MEM medium supplemented with FBS (10\%) and L-glutamine (2 mM). Cells are maintained in an incubator at $37^{\circ} \mathrm{C}$ with $5 \% \mathrm{CO}_{2}$.

\section{Animals and tumors}


$\mathrm{BALB} / \mathrm{c}$ nude male mice, 5 weeks old were used. Animals were housed in plastic cages inside a controlled ventilated rack with free access to water and food. All experiments were performed in accordance with national animal care guidelines (EC directive 86/609/CEE, French decree $n^{\circ} 87-848$ ). Tumor xenografts were achieved by subcutaneous injection of tumor cells suspension $\left(2.5 \times 10^{5}\right.$ cells in $\left.200 \mu \mathrm{PBS}\right)$ into the right flank. To follow tumor growth, tumor volume ( $\mathrm{V}$ in $\mathrm{mm} 3$ ) was measured with a caliper and was calculated as $\mathrm{V}=$ (length $\mathrm{x}$ width $\mathrm{x}$ thickness)/2.

Biodistribution study: ICP-MS analysis

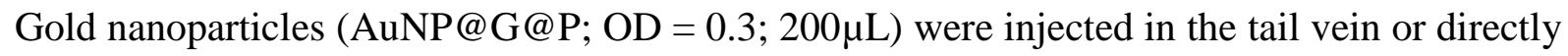
into the tumor, then $4 \mathrm{~h}$ or $24 \mathrm{~h}$ post-injection mice were sacrificed in order to take a blood sample and the following organs: tumor, liver, a piece of muscles, heart, brain, kidneys and spleen. Every sample was analyzed by ICP-MS to determine the amount of NP in each tissue $(\mu \mathrm{g} / \mathrm{kg})$

In vivo Plasmonic photothermal treatment (PPTT)

When tumors reached a volume of $200 \pm 50 \mathrm{~mm}^{3}$ (D0), mice were randomly assigned into 3 groups (5 mice per group). In the CTRL group, mice were not treated; in the Laser group, PBS $(100 \mu \mathrm{L})$ was injected into the tumor then the anesthetized mice received PPTT; in the AuNPs group, AuNP@G@P (100 $\mu \mathrm{L}$; OD = 0.3) was injected into the tumor then the anesthetized mice received PPTT. Tumor treatment was performed 1 hour after injection of PBS or AuNPs. Photothermal treatment consisted in a tumor irradiation with a $808 \mathrm{~nm}$ laser diode during 20 min with a power density of $1.5 \mathrm{~W} / \mathrm{cm}^{2}$.

In vivo evaluation of PPTT efficacy

Plasmonic photothermal treatment efficacy was assessed regarding the nanomaterial effects on tumor volume for PPT-treated mice relative to control vehicle-treated mice. Two 
evaluation criteria were used in parallel: (i) Growth inhibition, calculated as the ratio of the median tumor volume of AuNP-treated versus control groups : T/C, $\%=$ (median tumor volume of AuNP-treated group on day X / median tumor volume of control group on day X) X 100 , the optimal value, being the minimal T/C ratio which reflects the maximal tumor growth inhibition achieved; (ii) Relative area under the tumor growth curve, rAUC (\%), representative of the tumor growth curve as a whole, reflects the overall effect of a test compound over time. $\mathrm{rAUC}=[($ area under the tumor volume growth curve of the treated group / median area under the tumor volume growth curve of the control group) $\mathrm{x} \mathrm{100].} \mathrm{The}$ more active the compound, the lower the rAUC value.

\section{Statistical analysis.}

The results are shown as the mean \pm standard deviation. Data was analyzed by One-Way Analysis of Variance (ANOVA) followed by post-hoc comparisons by Tukey's HSD test. A probability level $<0.05$ was considered statistically significant. Calculations were performed using SigmaPlot 9 software. 


\section{ASSOCIATED CONTENT}

Supporting Information. Supplementary figures, schemes and tables are provided.

This material is available free of charge via the Internet at http://

Corresponding Author: annelaure.morel@ torskal.fr*

\section{Author Contributions}

The manuscript was written through contributions of all authors. All authors have given approval to the final version of the manuscript.

\section{ACKNOWLEDGMENT}

This work has been partly performed in TORSKAL Nanoscience, on the CNanoMat platform of the University Paris XIII and TMMU.

This work has been partly funded by BPI France, Europe (FEDER) and the Regional Council of La Réunion. We thankMs Céline FRECHINA, MrImade AIT ARSA, Dr Laura LALLEMAND and Dr Maya CESARI from CYROI platform for the biological tests. Support was provided by Sandra CASALE from University of Paris VI for TEM analysis. XPS Data were performed in PLACAMAT, Bordeaux by Christine LABRUGERE. Plants are originated from CAHEB. The preclinical batch was provided by Dr NazendeGundayTureli from Pharmjet MJR, Germany. 


\section{References}

[1] H. Jahangirian, E. Ghasemian lemraski, T. J. Webster, R. Rafiee-Moghaddam, et Y. Abdollahi, «A review of drug delivery systems based on nanotechnology and green chemistry: green nanomedicine », International Journal of Nanomedicine, vol. Volume 12, p. 2957- 2978, avr. 2017.

[2] A.-L. Morel, S. Giraud, A. Bialecki, H. Moustaoui, M. L. de La Chapelle, et J. Spadavecchia, «Green extraction of endemic plants to synthesize gold nanoparticles for theranostic applications », Frontiers in Laboratory Medicine, vol. 1, no 3, p. 158- 171, sept. 2017.

[3] S. K. Sivaraman, S. Kumar, et V. Santhanam, «Monodisperse sub-10nm gold nanoparticles by reversing the order of addition in Turkevich method - The role of chloroauric acid », Journal of Colloid and Interface Science, vol. 361, no 2, p. 543- 547, sept. 2011.

[4] E. B. Dickerson et al., «Gold nanorod assisted near-infrared plasmonic photothermal therapy (PPTT) of squamous cell carcinoma in mice », Cancer Letters, vol. 269, no 1, p. 57- 66, sept. 2008.

[5] L. Zilberberg et al., «Structure and Inhibitory Effects on Angiogenesis and Tumor Development of a New Vascular Endothelial Growth Inhibitor », Journal of Biological Chemistry, vol. 278, no 37, p. 35564- 35573, sept. 2003.

[6] S. Deshayes et al., "Click" Conjugation of Peptide on the Surface of Polymeric Nanoparticles for Targeting Tumor Angiogenesis », Pharmaceutical Research, vol. 28, no 7, p. 1631- 1642, juill. 2011.

[7] S. Brillant, J.-C. Pieribattesti, C. Marodon, Ethnopharmacologia, n³7, juin 2006 
[8] Sprogøe, K., Stærk, D., Jäger, A. K., Adsersen, A., Hansen, S. H., Witt, M., ... \& Jaroszewski, J. W. (2007). Targeted natural product isolation guided by HPLC-SPENMR: constituents of Hubertia species. Journal of natural products, 70(9), 1472-1477.

[9] M. Ben Haddada et al., « Endemic Plants: From Design to a New Way of Smart Hybrid Nanomaterials for Green Nanomedicine Applications », Journal of Nanomedicine \& Nanotechnology, vol. 09, no 05, 2018.

[10] W. Haiss, N. T. K. Thanh, J. Aveyard, et D. G. Fernig, «Determination of Size and Concentration of Gold Nanoparticles from UV-Vis Spectra », Analytical Chemistry, vol. 79, no 11, p. 4215- 4221, juin 2007.

[11] Fent, Genevieve M., et al. "Biodistribution of maltose and gum arabic hybrid gold nanoparticles after intravenous injection in juvenile swine." Nanomedicine: Nanotechnology, Biology and Medicine 5.2 (2009): 128-135.

[12] T. Stylianopoulos et R. K. Jain, «Design considerations for nanotherapeutics in oncology », Nanomedicine: Nanotechnology, Biology and Medicine, vol. 11, no 8, p. 1893- 1907, nov. 2015.

[13] A. K. Rengan, M. Jagtap, A. De, R. Banerjee, et R. Srivastava, « Multifunctional gold coated thermo-sensitive liposomes for multimodal imaging and photo-thermal therapy of breast cancer cells », Nanoscale, vol. 6, no 2, p. 916- 923, 2014.

[14] A. Basile, D. Biziato, G. V. Sherbet, P. Comi, et F. Cajone, « Hyperthermia inhibits cell proliferation and induces apoptosis: Relative signaling status of P53, S100A4, and Notch in heat sensitive and resistant cell lines », Journal of Cellular Biochemistry, vol. 103, no 1, p. 212- 220, janv. 2008.

[15] K. Sasaki, R. Calderheadt Glen, I. Chin, et K. Inomata, «To examine the adverse photothermal effects of extended dosage laser therapy in vivo on the skin and subcutaneous tissue in the rat model », Laser therapy, vol. 4, no 2, p. 69- 73, 1992. 
[16] L. R. Hirsch et al., «Nanoshell-Mediated Near-Infrared Thermal Therapy of Tumors under Magnetic Resonance Guidance », Proceedings of the National Academy of Sciences of the United States of America, vol. 100, no 23, p. 13549- 13554, 2003.

[17] W. I. Choi, J.-Y. Kim, C. Kang, C. C. Byeon, Y. H. Kim, et G. Tae, « Tumor Regression In Vivo by Photothermal Therapy Based on Gold-Nanorod-Loaded, Functional Nanocarriers », ACS Nano, vol. 5, no 3, p. 1995- 2003, mars 2011.

[18] P.-E. Le Renard, «Formulations pour le traitement local de tumeurs solides par hyperthermie à médiation magnétique », Université de Nancy, 2011.

[19] D. Hanahan, R. A. Weinberg, « Hallmarks of Cancer: The Next Generation », Cell, vol. 144, no 5, p. 646- 674, mars 2011.

[20] Corbett TH, Valeriote FA, Demchik L, Polin L, Panchapor C, Pugh S, White K, Knight J, Jones J, Jones L, LoRusso P, Foster B, Wiegand RA, Lisow L, Golakoti T, Heltzel CE, Ogino J, Patterson GM, Moore RE., «Preclinical anticancer activity of cryptophycin-8. », J Exp Ther Oncol., vol. 1, no 2, p. 95- 108. 